\title{
Psychological consequences of childhood obesity: psychiatric comorbidity and prevention
}

This article was published in the following Dove Press journal:

Adolescent Health, Medicine and Therapeutics

14 November 2016

Number of times this article has been viewed

\author{
Jean Rankin' \\ Lynsay Matthews ${ }^{2}$ \\ Stephen Cobley ${ }^{3}$ \\ Ahreum Han ${ }^{3}$ \\ Ross Sanders ${ }^{3}$ \\ Huw D Wiltshire ${ }^{4}$ \\ Julien S Baker ${ }^{5}$
}

'Department of Maternal and Child Health, University of the West of Scotland, Paisley, ${ }^{2} \mathrm{MRC} / \mathrm{CSO}$ Social and Public Health Sciences Unit, Institute of Health and Wellbeing, University of Glasgow, Glasgow, Scotland; ${ }^{3}$ Department of Exercise and Sport Science, University of Sydney, Sydney, Australia; ${ }^{4}$ Cardiff School of Sport/Ysgol Chwaraeon Caerdydd, Cardiff Metropolitan University, Cardiff, UK; ${ }^{5}$ School of Science and Sport, Institute of Clinical Exercise and Health Science, University of the West of Scotland, Hamilton, Scotland

Correspondence: Jean Rankin Department of Maternal and Child Health, University of the West of Scotland, High Street, Paisley, Scotland PAI 2BE

Email j.rankin@uws.ac.uk
Abstract: Childhood obesity is one of the most serious public health challenges of the 21 st century with far-reaching and enduring adverse consequences for health outcomes. Over 42 million children $<5$ years worldwide are estimated to be overweight (OW) or obese (OB), and if current trends continue, then an estimated 70 million children will be OW or OB by 2025 . The purpose of this review was to focus on psychiatric, psychological, and psychosocial consequences of childhood obesity (OBy) to include a broad range of international studies. The aim was to establish what has recently changed in relation to the common psychological consequences associated with childhood OBy. A systematic search was conducted in MEDLINE, Web of Science, and the Cochrane Library for articles presenting information on the identification or prevention of psychiatric morbidity in childhood obesity. Relevant data were extracted and narratively reviewed. Findings established childhood OW/OBy was negatively associated with psychological comorbidities, such as depression, poorer perceived lower scores on health-related quality of life, emotional and behavioral disorders, and self-esteem during childhood. Evidence related to the association between attention-deficit/hyperactivity disorder (ADHD) and OBy remains unconvincing because of various findings from studies. OW children were more likely to experience multiple associated psychosocial problems than their healthy-weight peers, which may be adversely influenced by OBy stigma, teasing, and bullying. OBy stigma, teasing, and bullying are pervasive and can have serious consequences for emotional and physical health and performance. It remains unclear as to whether psychiatric disorders and psychological problems are a cause or a consequence of childhood obesity or whether common factors promote both obesity and psychiatric disturbances in susceptible children and adolescents. A cohesive and strategic approach to tackle this current obesity epidemic is necessary to combat this increasing trend which is compromising the health and well-being of the young generation and seriously impinging on resources and economic costs.

Keywords: pediatric obesity, psychological comorbidity, mental health, ADHD, depression, anxiety, obesity stigma, teasing, bullying

\section{Introduction}

Childhood obesity is one of the most serious public health challenges of the $21 \mathrm{st}$ century. Over 42 million children $<5$ years worldwide are estimated to be overweight (OW) or obese (OB). ${ }^{1,2} \mathrm{OW}$ and obesity (OBy), an established problem in high-income countries, is also an increasing problem in low- to middle-income countries (Table 1). More alarmingly, the increasing rate of childhood OW and $\mathrm{OBy}$ in developing countries is now $>30 \%$ higher than that in developed countries. If current trends continue, then 
Table I Global incidence of overweight and obesity in childhood

- Of the 42 million overweight children worldwide, $\sim 31$ million live in developing countries'

- In the United States, childhood obesity incidence has more than doubled in children and quadrupled in adolescents in the past 30 years. One-third of the US children/adolescents in the general population are currently overweight/obese ${ }^{86,87}$

- Overweight/obesity in children aged II-13 years across 36 countries in WHO European region ranges from $5 \%$ to $>25 \%^{88}$

- Australia, with the sixth highest prevalence of the population being overweight or obese among OECD countries ${ }^{89}$, has $\sim 25 \%$ of overweight children aged $2-16$ years with $6 \%$ being classified as obese ${ }^{2,90}$

- In the last 25 years, the number of overweight or obese children living in the African continent has surged from 5.4 million to 10.3 million.

This means $25 \%$ of all overweight or obese preschool age children live in the WHO African regions'

Abbreviations: $\mathrm{OECD}$, Organization for Economic Cooperation and Development; WHO, World Health Organization.

an estimated 70 million children will be OW or OB by 2025 , making this a leading health problem. ${ }^{2}$

Childhood and adolescent OBy has far-reaching and enduring adverse consequences for health outcomes. ${ }^{3,4}$ In particular, the onset of psychiatric and psychological symptoms and disorders is more prevalent in OB children and young adults. Research has confirmed an association between childhood OW and OBy, psychiatric and psychological disorders, and onward detrimental effects on the psychosocial domain ${ }^{5-7}$ and overall quality of life (QoL). ${ }^{8,9}$ In turn, these can also compound their physical and medical health outcomes., Emerging research might strengthen the current body of knowledge in this area. Further review is required to explore the extent and implications of psychological comorbidities as well as identify important gaps for future research.

This review focuses on psychiatric, psychological, and psychosocial consequences of childhood OBy. It is the most recent review of this type and includes a broad range of studies involving numerous countries with varying methodologies. The aim was to establish what has recently changed in relation to the common psychological consequences associated with childhood OBy.

\section{Methods}

\section{Data sources and searches}

Three databases were searched, including MEDLINE (PubMed), Web of Science, and Cochrane Library. Search terms were developed with input from an subject expert librarian (Table 2). The search terms and strategy attempted to capture new information not included in previous reviews, including both prevention and treatment options, and findings from multiple countries. The full search was undertaken by
Table 2 Complete list of search terms

(childhood obesity or pediatric obesity or obese children or obese child) and (comorbidity or comorbidities or co-morbidity or co-morbidities) and (identification or diagnosis) and (prevention or treatment or treatments or therapy or therapies or intervention or interventions) and (psychiatric or psychological or cognitherapy or cognitive behavio?r therapy or motivational enhancement or antipsychotics or body image or body image disturbance or body dissatisfaction or body shape discontent or self-esteem or depression or anxiety or disordered eating or weight stigmatization or weight bias or bullying or stress or cognitive impairment or attention-deficit disorder or low health-related quality of life or self-perception or long-term effects or school performance)

one reviewer (JR). Then, another reviewer (LM) independently examined the titles and abstracts to identify suitable publications matching the selection criteria. Later, full texts were obtained for relevant articles and examined for inclusion in the final collection of review literature.

\section{Study selection}

All publications presenting information on the identification or prevention of psychiatric morbidity in childhood obesity were included. Articles for review were excluded if published before 2006, were unavailable in English, focused on medi$\mathrm{cal} /$ physiological outcomes or on obesity in adulthood (the cutoff age for adulthood varied and was determined by the authors of individual papers).

\section{Preliminary search results}

Databases were searched between June 13 and 17, 2016. Initial search results are presented in Figure 1. Of 53 studies, 16 explored depression and anxiety, 17 investigated attentiondeficit/hyperactivity disorder (ADHD) and conduct disorders (of which one also explored depression and anxiety), and 30 focused on other psychological comorbidities (of which 9 also included depression, anxiety, and/or ADHD).

\section{Results}

The reviewed 53 studies are summarized in Tables 3-5 and are presented narratively below in relation to: 1) depression and anxiety, 2) ADHD, and 3) other psychological comorbidities including self-esteem, QoL, stigmatization, and eating disorders. Abbreviations for all outcome measures are detailed in Table 6 .

\section{Depression and anxiety}

Previous research findings about the relationship between depression and childhood OW/OBy suggest that weight gain during adolescence may be related to depression, negative mood states, and poor self-esteem. ${ }^{7,10}$ 


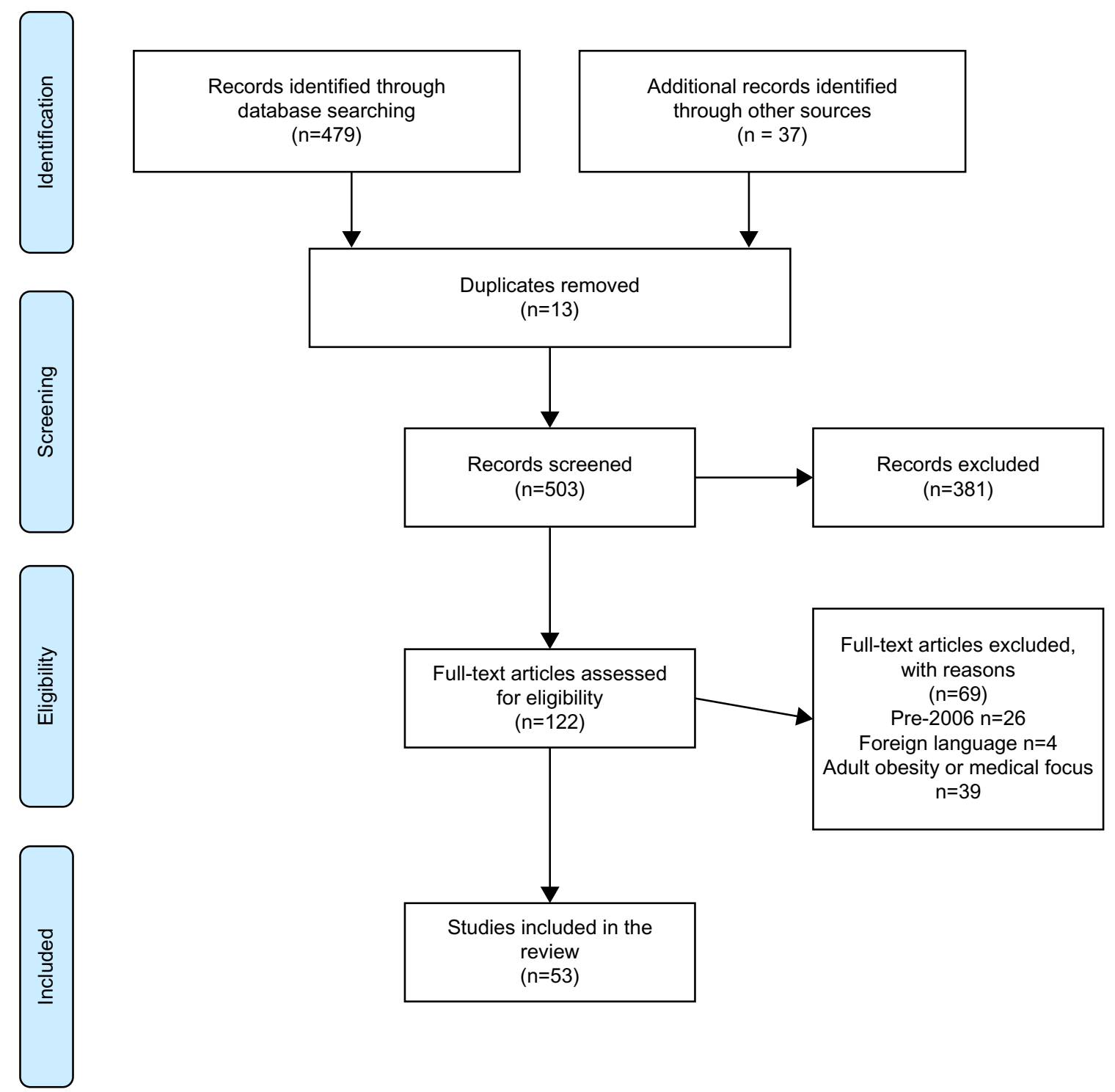

Figure I PRISMA flow diagram of search results.

Abbreviation: PRISMA, Preferred Reporting Items for Systematic Reviews and Meta-Analyses.

In relation to depression and anxiety, Table 3 summarizes 16 studies that are currently reviewed. Diagnosis for depression and anxiety was confirmed either through diagnostic or clinical interview in 9 studies $^{5,11-18}$ or through specifically focused validated questionnaires in 7 studies. ${ }^{19-25}$ Body mass index (BMI) was obtained through direct measurement, from documentation/clinical records or self-report, and body weight status was determined using national and international reference data and cutoff points criteria. ${ }^{5,11-25}$ Study designs included prospective longitudinal, ${ }^{13,14,18,20,23}$ cross-sectional, ${ }^{15,16,19,21,22}$ populationbased, ${ }^{25}$ cohort,${ }^{24}$ clinical cohort, ${ }^{11,12}$ and retrospective studies. ${ }^{5,17}$

Numerous studies continue to report an association between depression and childhood OBy. ${ }^{14-16,21,22,26}$ Anxiety disorders and stress associated with childhood OW/OBy are less well documented. ${ }^{14,16,24}$ To date, related research studies have reported mixed findings.
Study findings varied in relation to the strength of association between depression and childhood OBy. $.^{11,15-17,19,21} \mathrm{OW} /$ OB children, compared with normal weight children, were found to be significantly more likely to experience depression as diagnosed by medical interview, ${ }^{15,16}$ with evidence that increasing weight in children was associated with increasing levels of psychosocial distress which is significantly correlated with depression, diagnosed by self-reported questionnaire. ${ }^{21}$ Other studies of childhood OW/OBy did not support these findings and reported the prevalence of depression (medical diagnosis) being only modestly greater than the general population, ${ }^{11}$ or having a weak association, as assessed by Child Depression Inventory (CDI) questionnaire.$^{19}$ In $\mathrm{OB}$ children, no statistically significant difference was found in the rates of most common psychiatric disorders including medical diagnosed depression. ${ }^{5}$ 


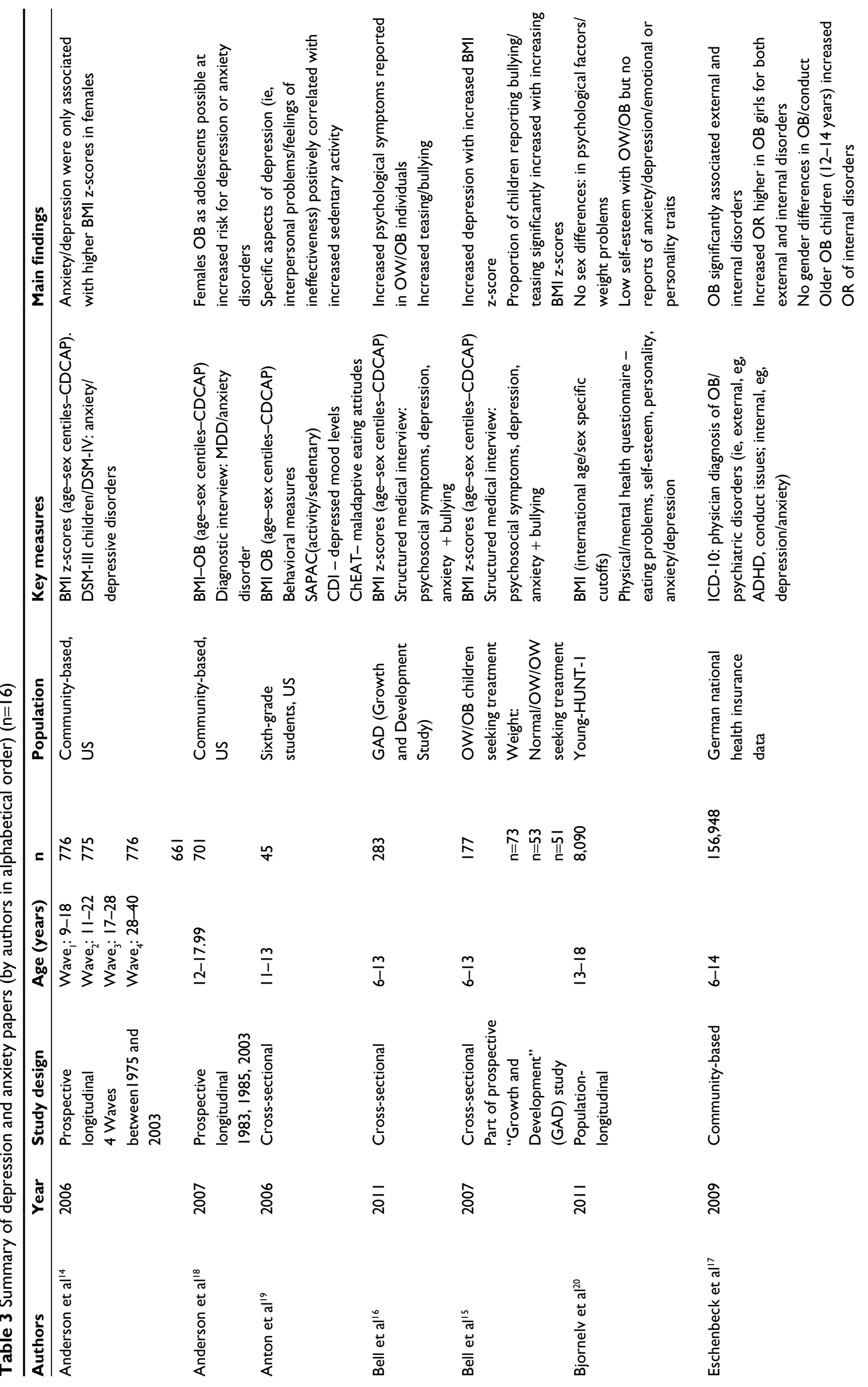



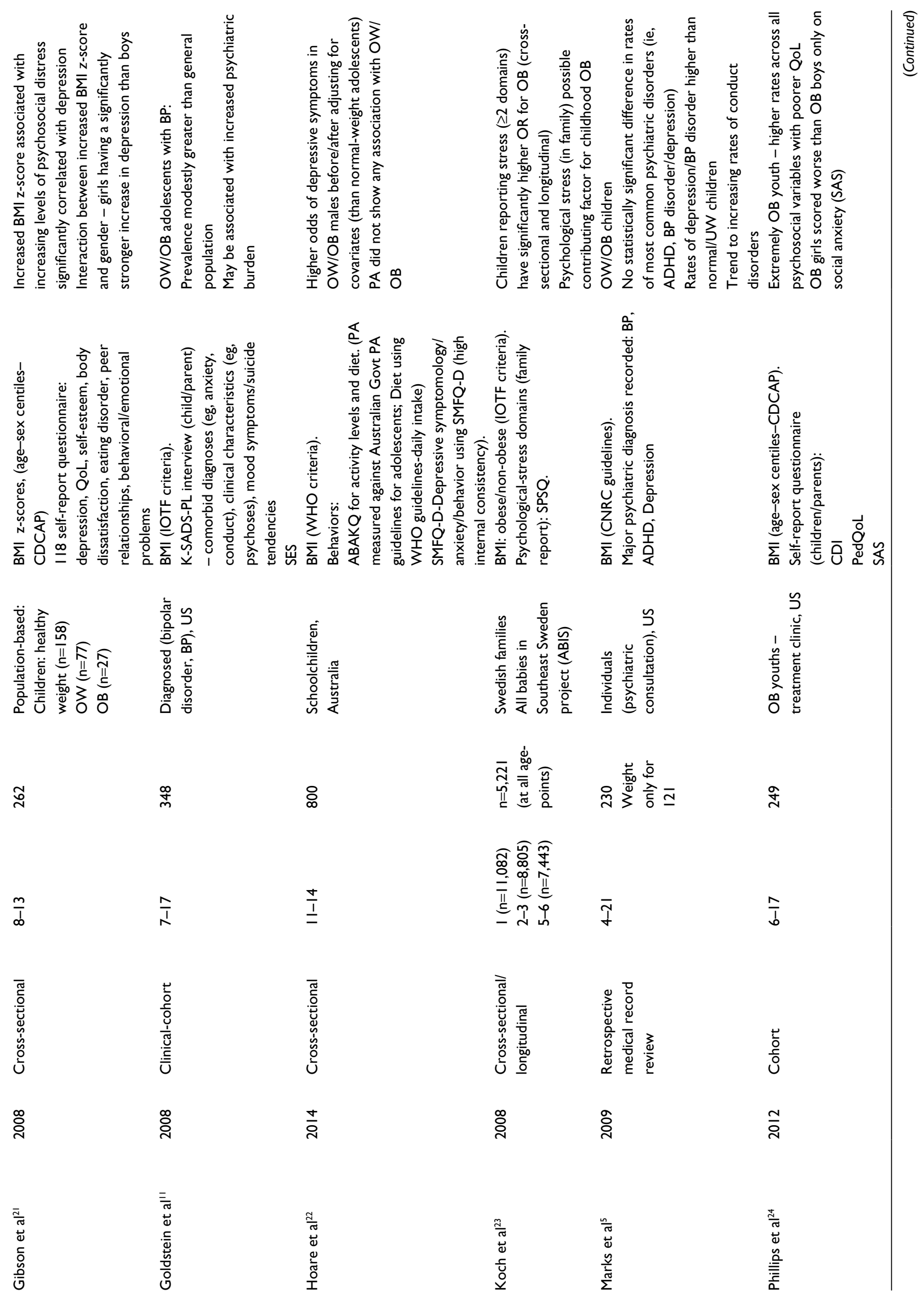


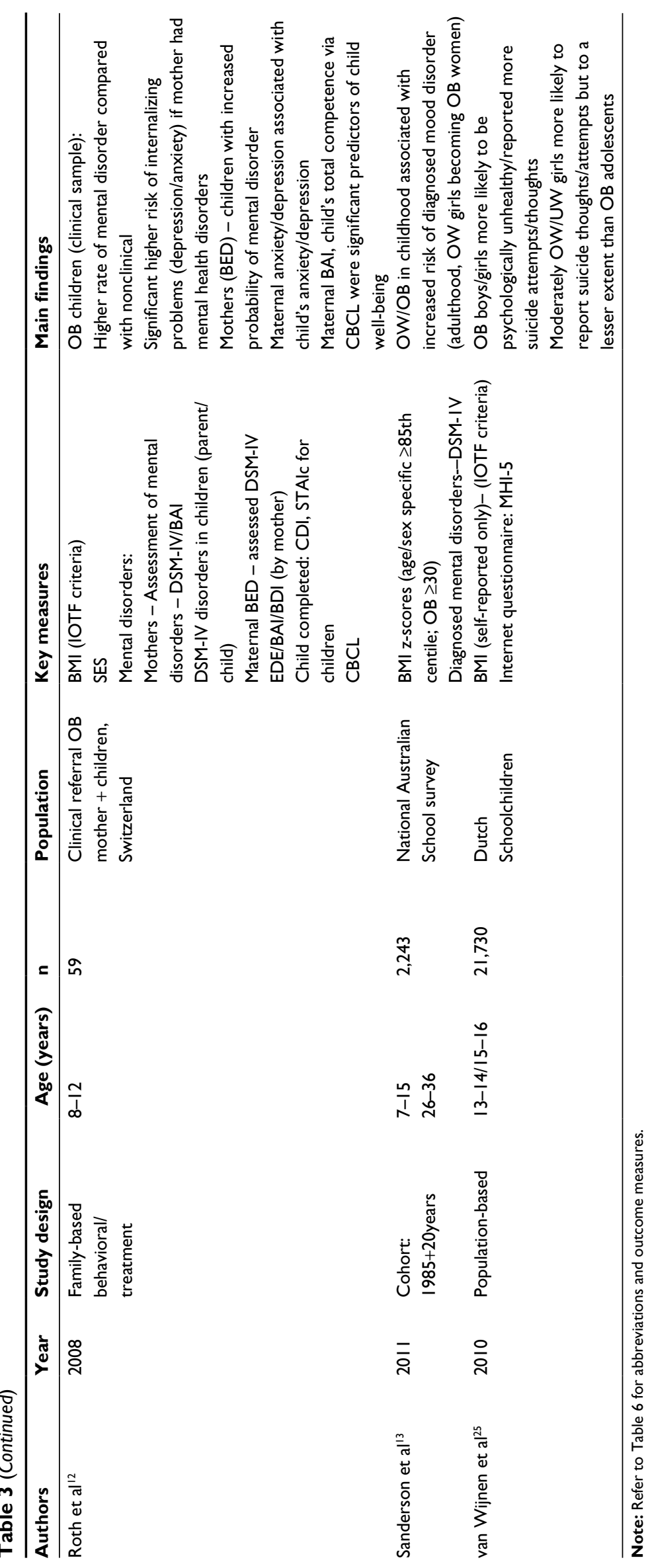




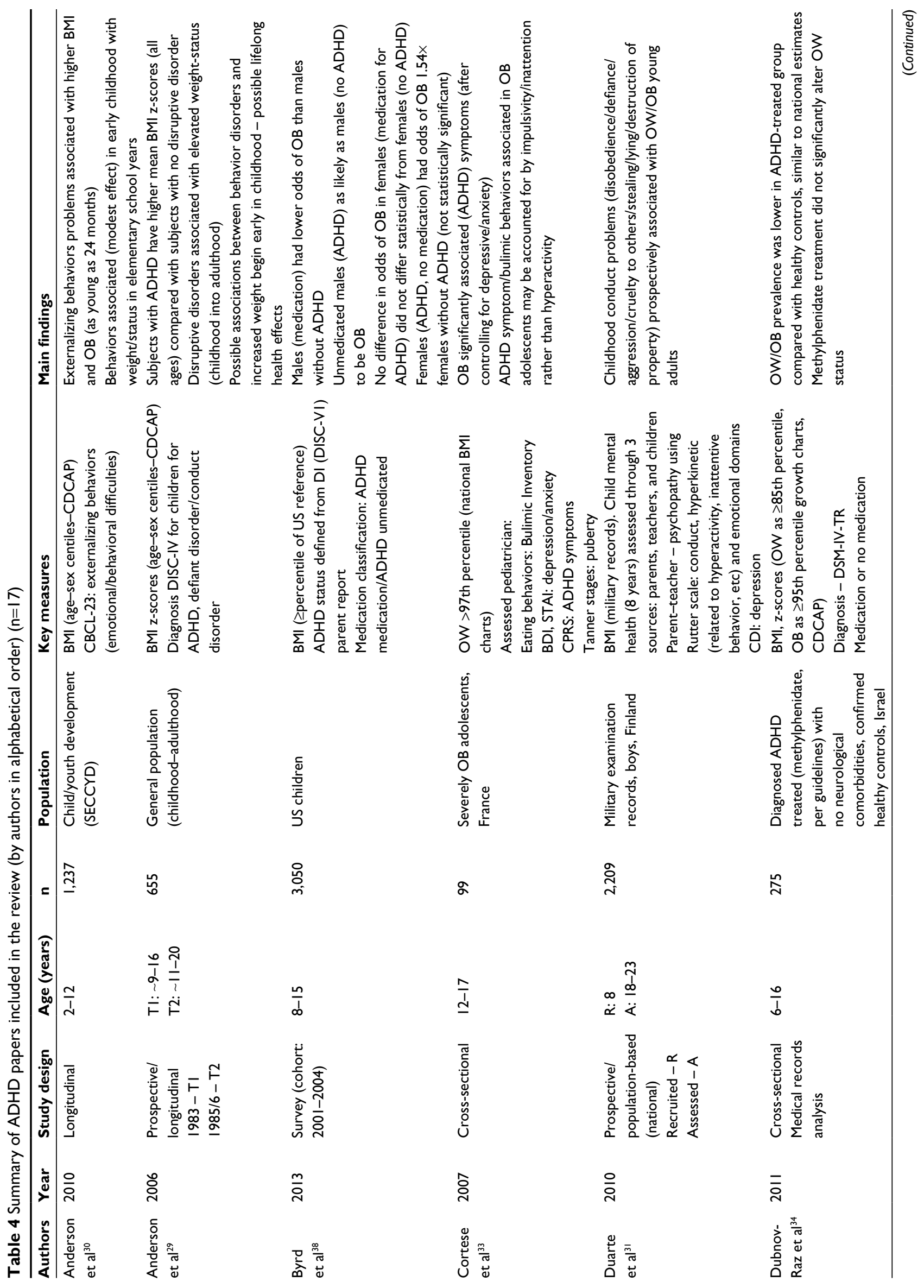




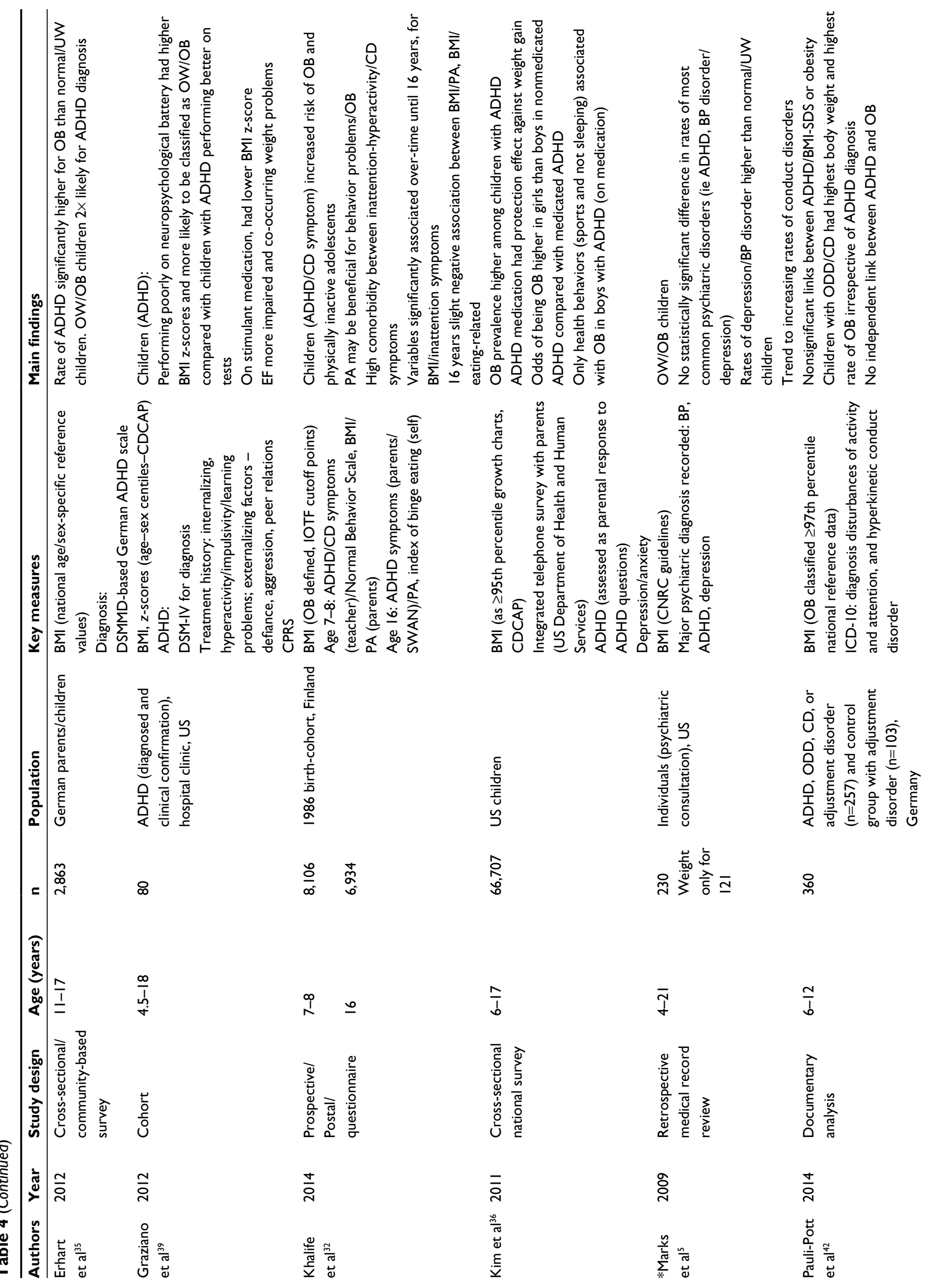



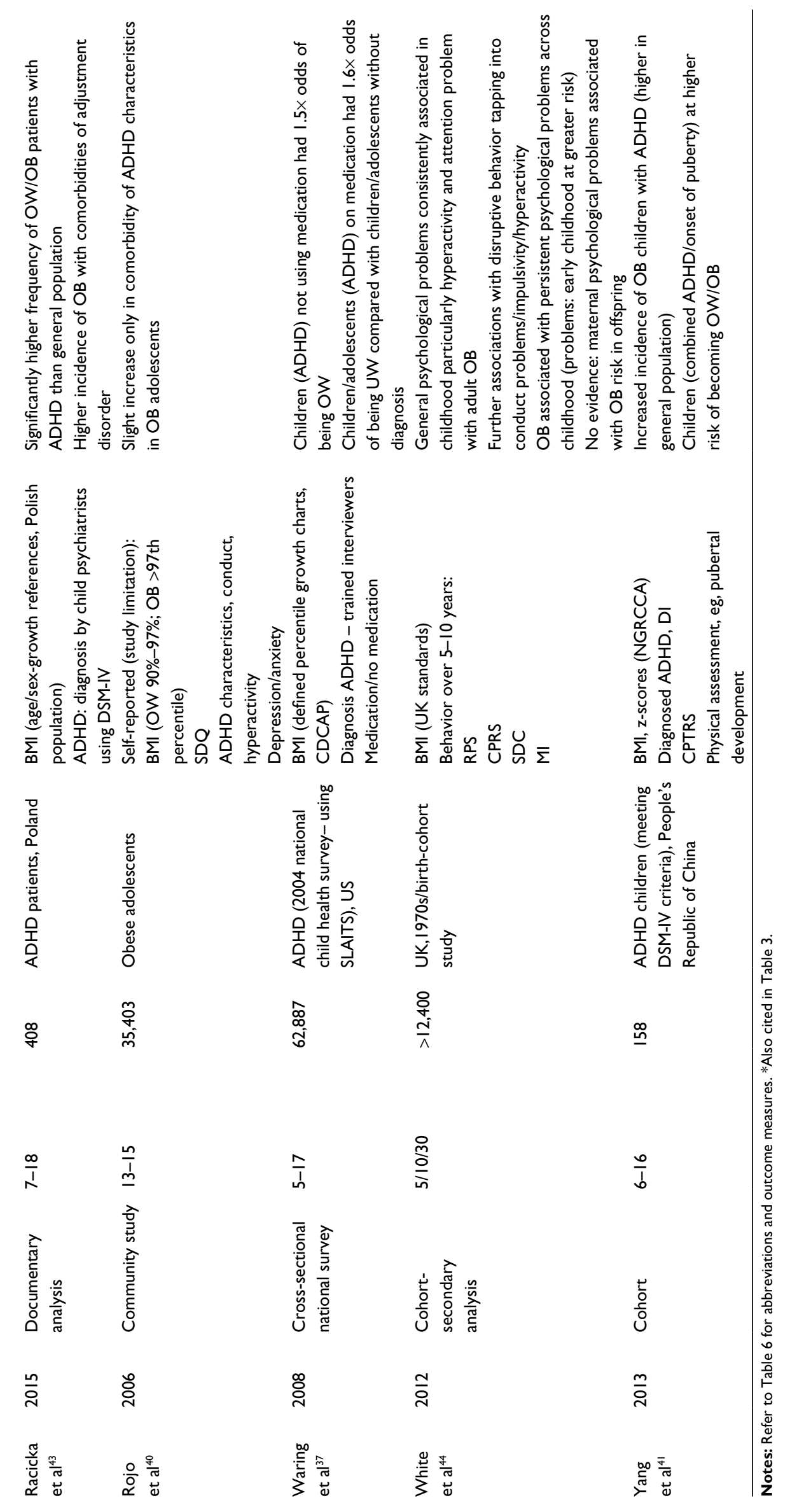


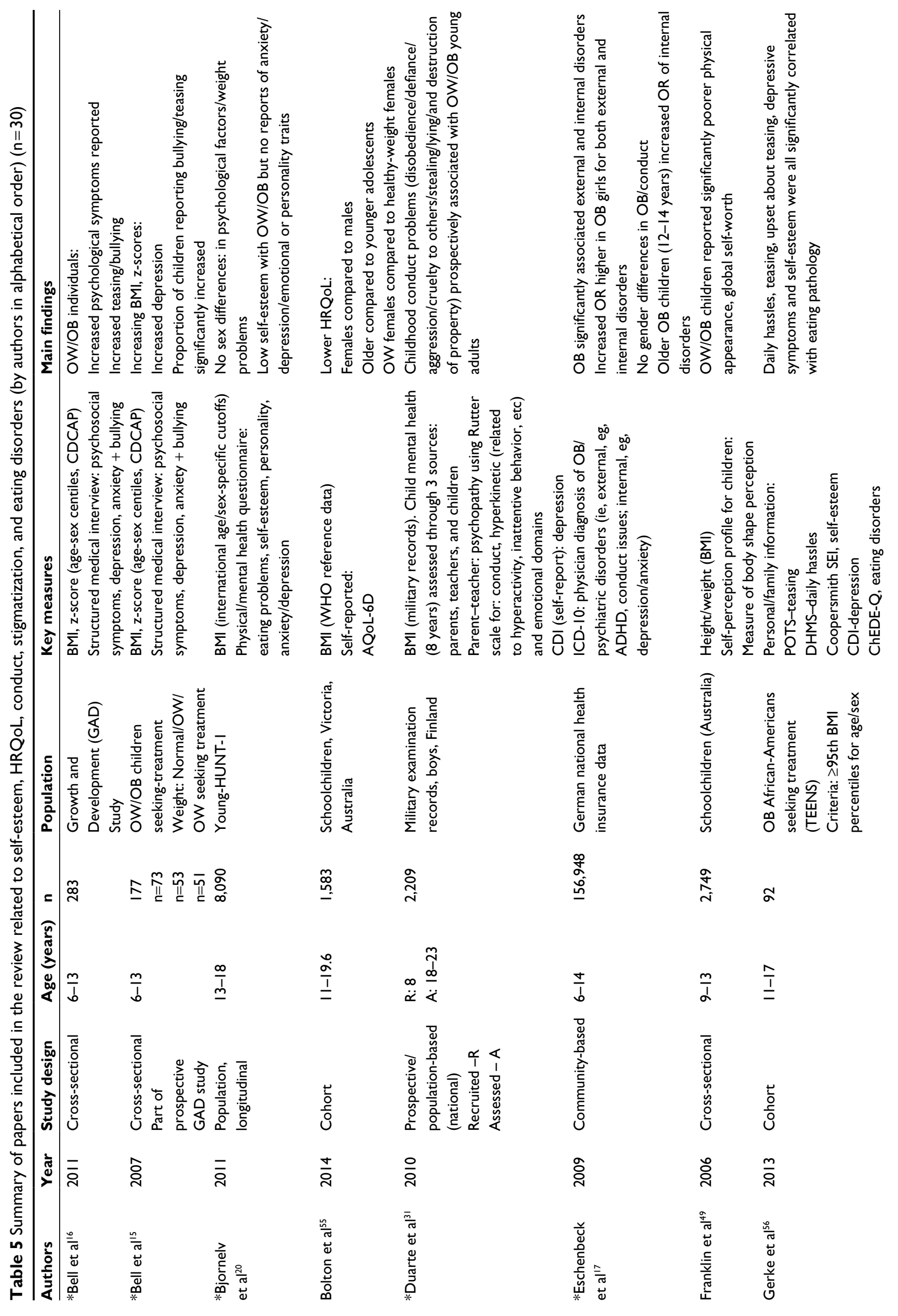



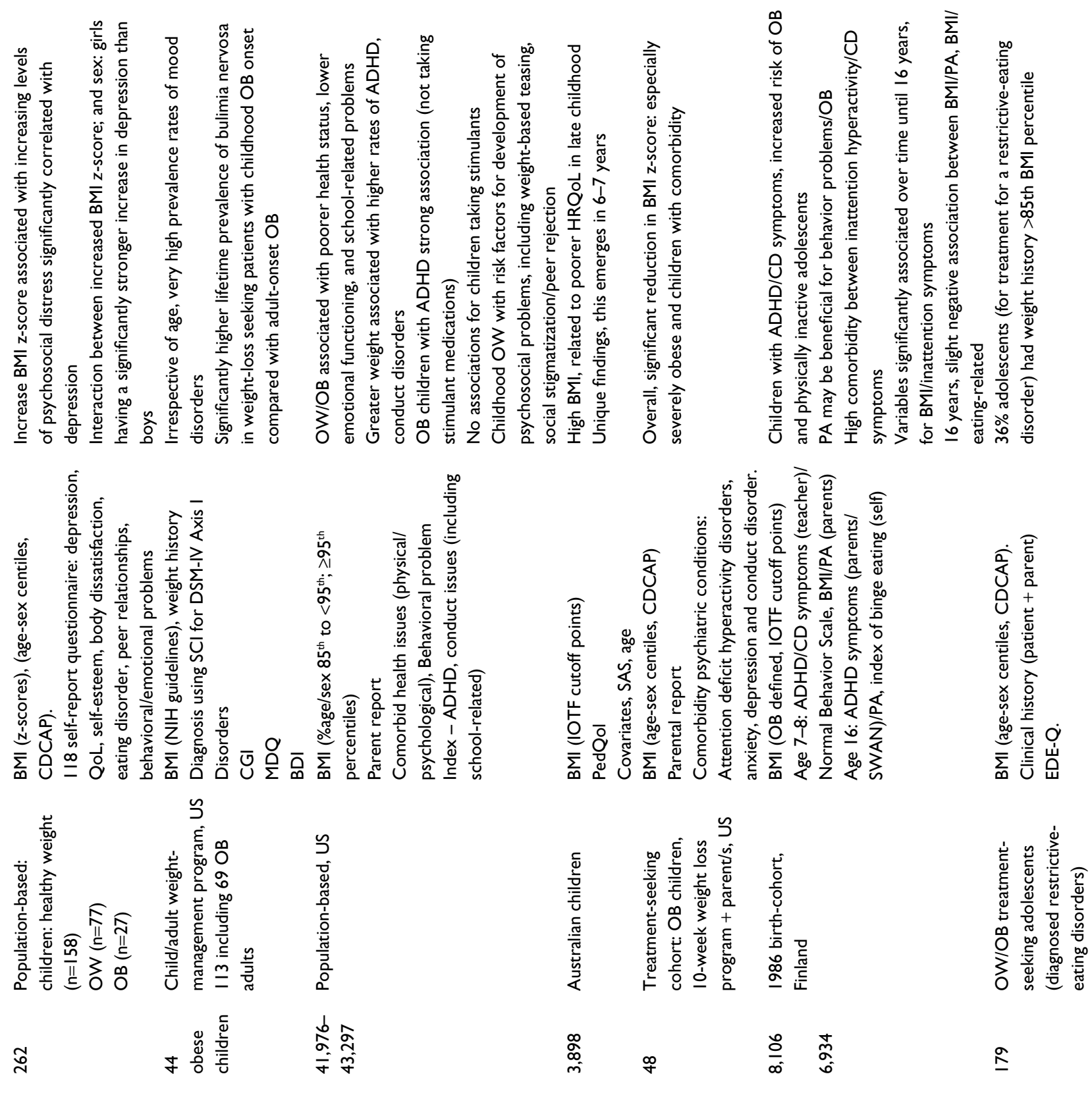

$\stackrel{2}{1}$

f

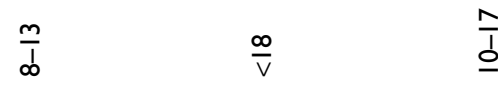

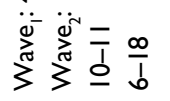

$\stackrel{\infty}{\Lambda} \underline{0}$

옹

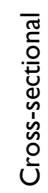
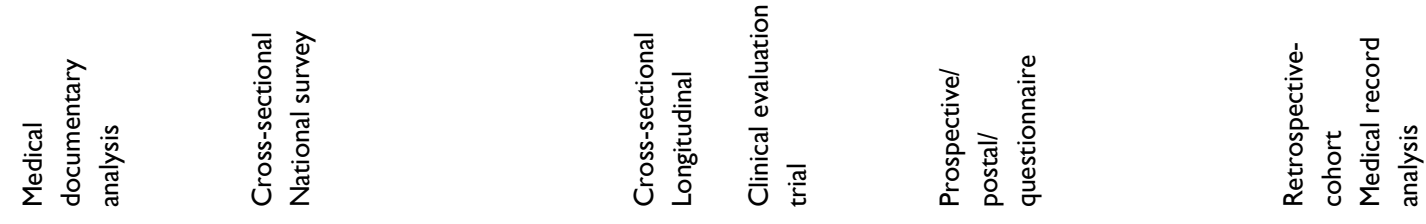

$\stackrel{\text { ڤ }}{\circ}$

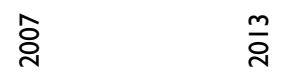

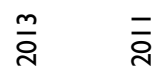

$\frac{4}{2}$

늠

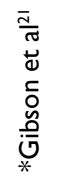

$\frac{0}{\frac{0}{4}}$

$\frac{0}{0}$
$\frac{0}{0}$
$\frac{0}{\frac{0}{5}}$
$\frac{0}{1}$

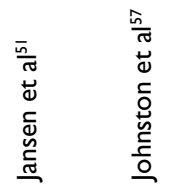

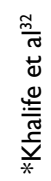

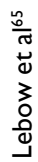




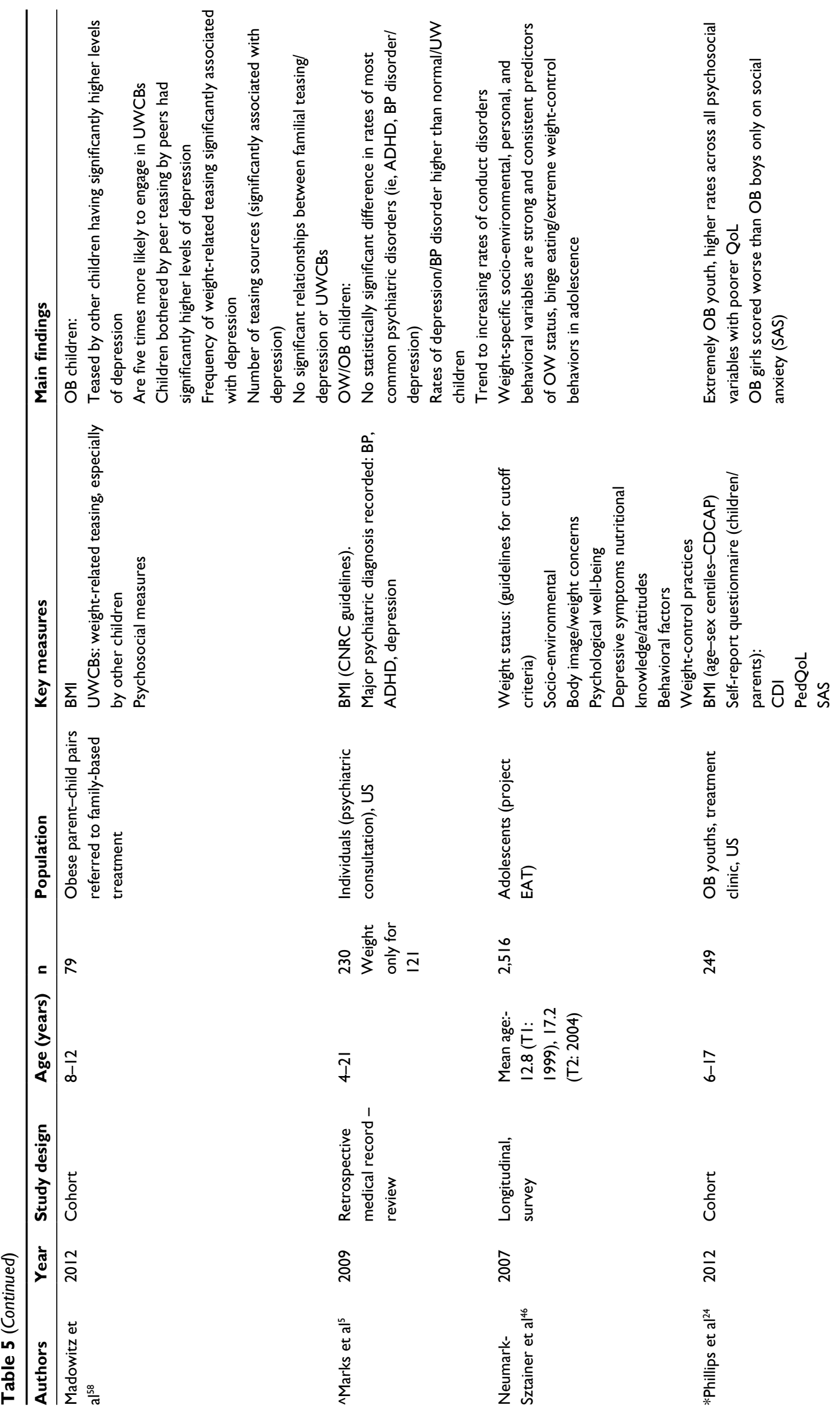



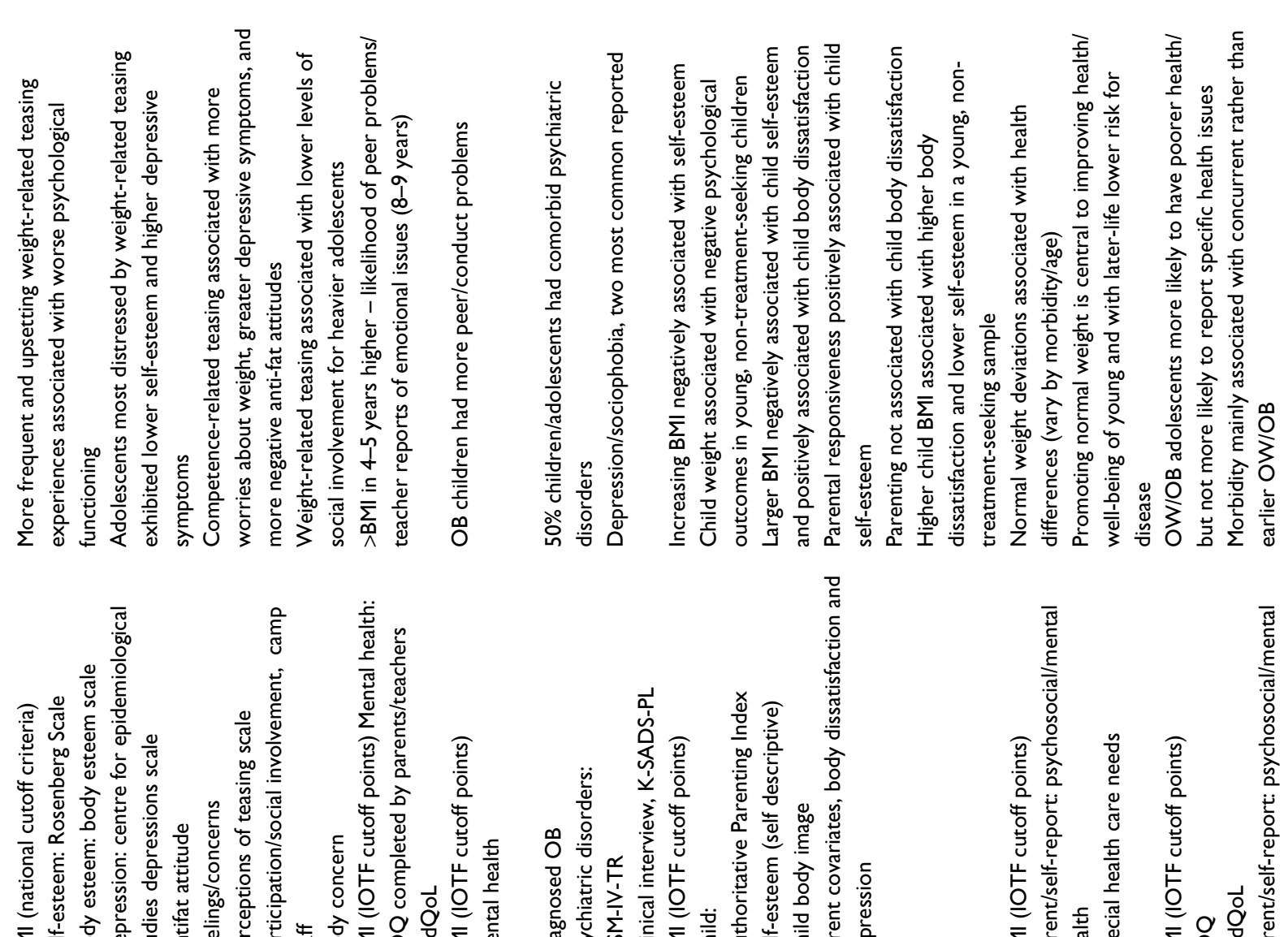

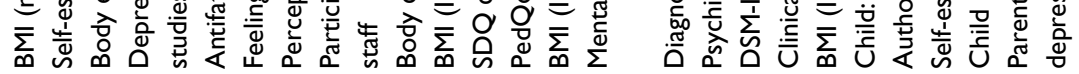
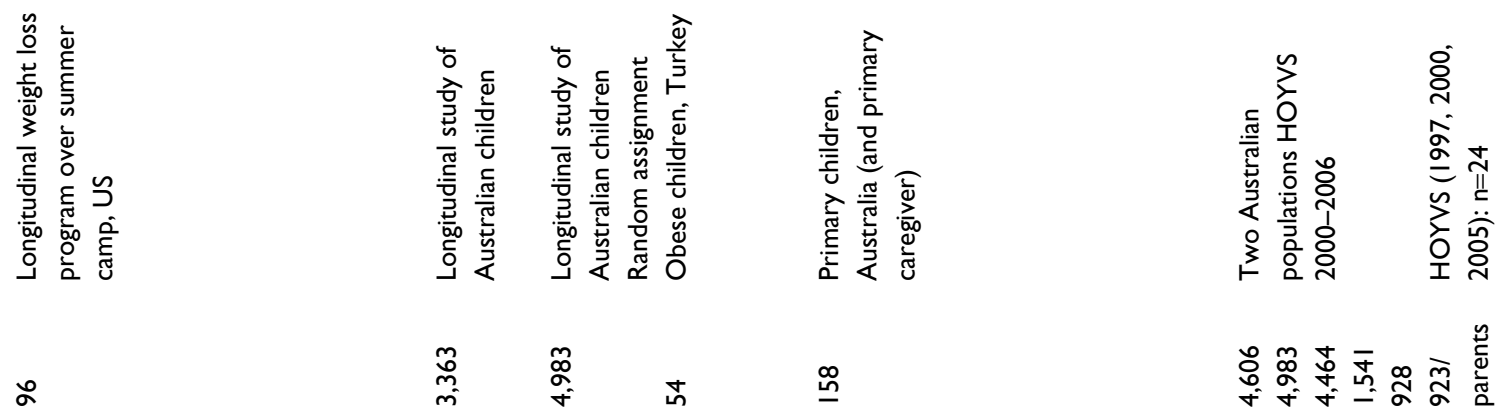

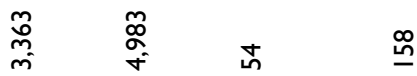

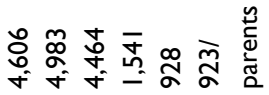

$\stackrel{\infty}{\stackrel{\infty}{d}}$

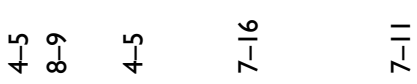

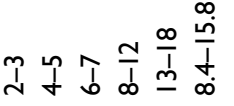

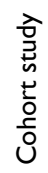

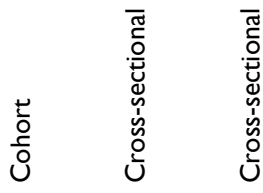

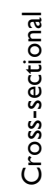
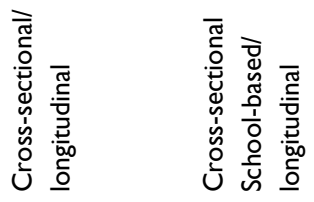

高

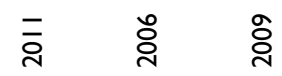

⿳亠口冋

i

음

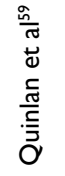

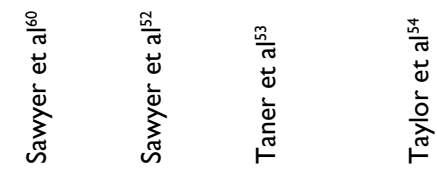

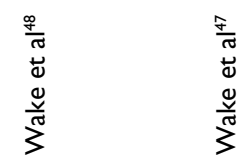




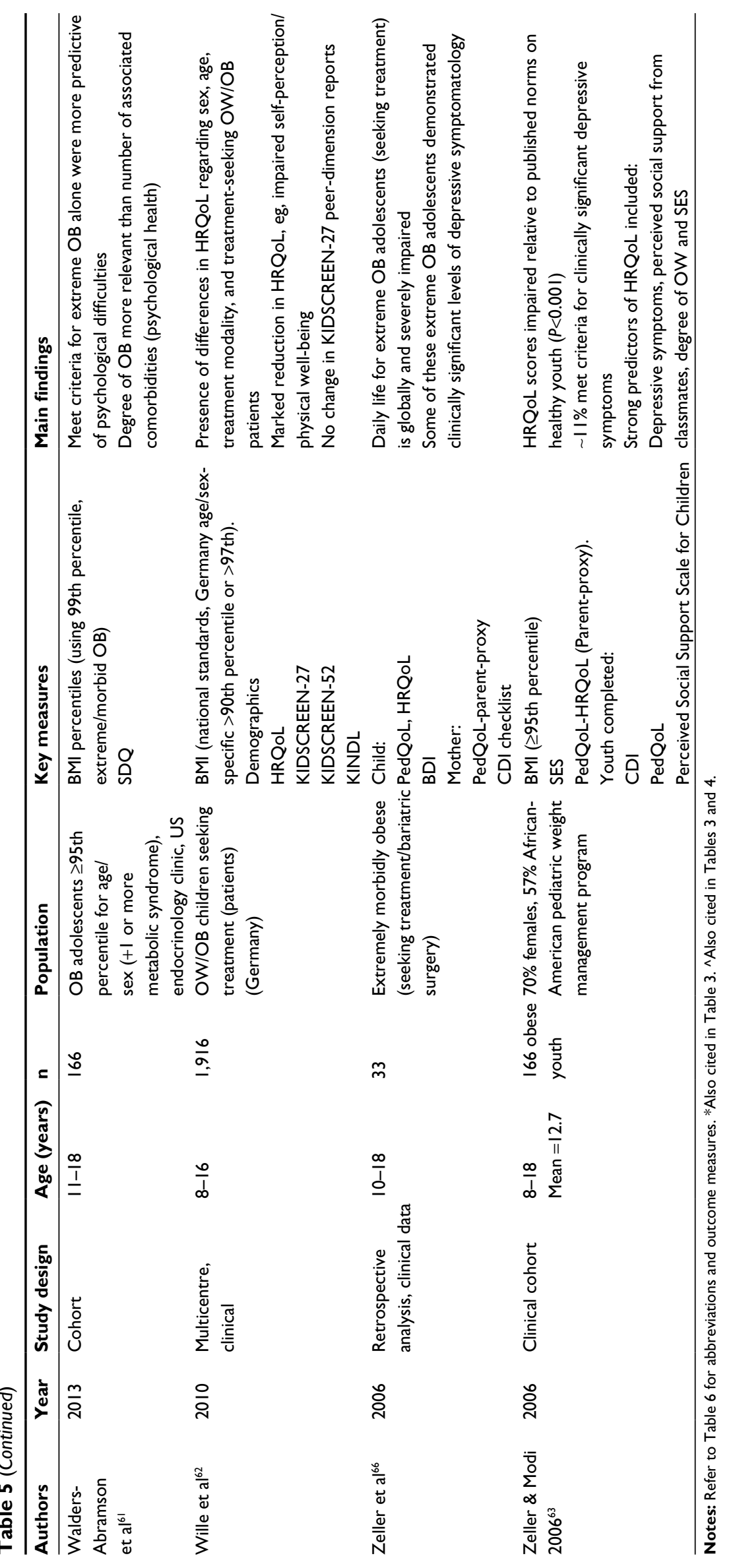


Table 6 List of abbreviations and outcome measures cited in Tables 3-5

\begin{tabular}{|c|c|}
\hline ABAKQ & Adolescent Behaviours, Attitudes, and Knowledge Questionnaire \\
\hline ADHD & Attention-Deficit/Hyperactivity Disorder \\
\hline AQoL-6D & Assessment of Quality of Life-6D scale \\
\hline BAI & Becks Anxiety Inventory Scale (validated tool) \\
\hline BDI & Becks Depression Inventory Scale (validated tool) \\
\hline BED & Binge eating disorder \\
\hline BMI & Body mass index: weight/height \\
\hline BMI-SDS & BMI Standard Deviation Score \\
\hline BP & Bipolar (mental health disorder) \\
\hline CBCL & Child Behavior Checklist (validated tool) \\
\hline CBCL-23 & Child Behavior Checklist 23 items \\
\hline CDCAP & Centre for Disease Control and Prevention. Using BMI centiles for age/sex-specific reference \\
\hline CDI & Child Depression Inventory (validated tool) \\
\hline CD & Conduct disorders \\
\hline CDI & Children's Depressive Symptoms Inventory (validated tool) \\
\hline CES-DC & Center for Epidemiological Studies Depression Scale for Children \\
\hline CGI & Clinical Global Impression (severity of mood and eating disorders) \\
\hline ChEAT & The Children’s Eating Attitudes Test \\
\hline ChEDE-Q & Children's Eating Disorder Examination Questionnaire \\
\hline CNRC & Children's Nutrition Research Center, US \\
\hline CPRS & Connors Parenting Rating Scale \\
\hline CPTRS & Connors Parent and Teacher Rating Scale \\
\hline DHMS & Daily Hassle Microsystem Scale \\
\hline DI & Diagnostic Interview \\
\hline DISC-IV & Diagnostic Interview Schedule for Children \\
\hline DISC-VI & Diagnostic Interview Schedule for Children 6th Edition \\
\hline DSM-III & Diagnostic and Statistical Manual of Mental Disorders - 3rd Edition \\
\hline DSM-IV & Diagnostic and Statistical Manual of Mental Disorders - 4th Edition \\
\hline DSM-IV-TR & Diagnostic and Statistical Manual of Mental Disorders - 4th Edition, text revision \\
\hline DSMMD & Diagnostic and Statistical Manual of Mental Disorders \\
\hline EAT & Eating Amongst Teens \\
\hline EDE & Eating Disorder Examination \\
\hline EDE-Q & Eating Disorder Examination Self-Report Questionnaire \\
\hline $\mathrm{EF}$ & Executive Functioning \\
\hline HOYVS & Health of Young Victorians' Study \\
\hline HRQoL & Health-Related Quality of Life \\
\hline ICD-10 & ICD-I0 is the 10th revision of the International Statistical Classification of Diseases and Related Health Problems by WHO \\
\hline IOTF & International Obesity Task force (reference data with cutoff points for weight status) \\
\hline K-SADS-PL & Schedule for Affective Disorders and Schizophrenia for School-age Children: present and lifetime version (validated tool) \\
\hline KIDSCREEN-27 & $\begin{array}{l}\text { Generic HRQoL for youths aged } 8-18 \text { years: subscales physical well-being, psychological well-being, autonomy and } \\
\text { parents, social support and peers, school environment (validated tool) }\end{array}$ \\
\hline KIDSCREEN-52 & Self-perception of security and satisfaction, eg, appearance (internal consistency) \\
\hline KINDL & Measure HRQoL for children and adolescents - captures experiences associated with OW/OB children \\
\hline MDD & Major depressive disorder \\
\hline MDQ & Mood Disorder Questionnaire \\
\hline MHI-5 & Mental Health Inventory-5 (validated tool). \\
\hline MI & Malaise Inventory \\
\hline NGRCCA & National Growth Reference for Chinese Children and Adolescents \\
\hline $\mathrm{NIH}$ & National Institute of Health \\
\hline $\mathrm{OB}$ & Obese \\
\hline ODD & Oppositional Defiant Disorder \\
\hline OR & Odds ratio \\
\hline OW & Overweight \\
\hline PA & Physical activity \\
\hline PedQol & Pediatric Quality of Life inventory (validated tool) \\
\hline POTS & Perceptions of Teasing Scale (validated tool) \\
\hline QoL & Quality of life \\
\hline RPS & Rutter Parent Scale \\
\hline SAPAC & Self-Administered Physical Activity Checklist (validated tool) \\
\hline
\end{tabular}


Table 6 (Continued)

\begin{tabular}{ll}
\hline SAS & Social Anxiety Scale (validated tool) \\
SCID & Structured Clinical Examination for DSM-IV (validated) \\
SDC & Social Development Scale \\
SDQ & Strengths and Difficulties Questionnaire (validated tool) \\
SECCYD & Study of Early Child Care and Youth Development \\
SEI & Self-Esteem Inventory (validated tool) \\
SES & Socio-Economic Status \\
SLAITS & State and Local Area Telephone Survey \\
SMFQ-D & Short Moods and Feelings Questionnaire (high internal consistency) \\
SPSQ & Swedish Parenting Stress Questionnaire (4 domains-SPSQ: life-events/social support, frequency of exposure [validated tool]) \\
STAI/STAlc & State Trait Anxiety Inventory/for Children (validated tool) \\
SWAN & Strengths/Weaknesses of ADHD/Normal Behavior \\
SPSQ & Swedish Parenting Stress Questionnaire (validated tool) \\
TEENS & Teaching, Encouragement, Exercise, Nutrition, Support Program \\
UW & Underweight \\
UWCBs & Unhealthy Weight Control Behaviors \\
WHO & World Health Organization \\
\hline
\end{tabular}

Only a small number of studies have reported sex differences in $\mathrm{OW} / \mathrm{OB}$ children/adolescents in relation to depression/ anxiety. ${ }^{14,21,22} \mathrm{OW} / \mathrm{OB}$ girls were reported to have a significantly greater increase in depression than OW/OB boys, ${ }^{21}$ with greater odds of developing depression and anxiety with increasing weight. ${ }^{14} \mathrm{OB}$ girls also demonstrated more social anxiety than OB boys. ${ }^{24}$ In contrast, OW/OB boys were found to be at higher odds of depressive symptoms than boys of normal weight. ${ }^{22}$

Other relevant findings of interest relate to the older OB child (12-14 years) having an increased chance of developing depression and other internalizing disorders such as anxiety and paranoia. ${ }^{17}$ Children also reporting stress on several levels have a significantly higher odds for becoming OB. ${ }^{23}$

Findings from studies suggest greater psychopathology among OW/OB adolescents than non-OB adolescents. ${ }^{11,25,27}$ $\mathrm{OB}$ children/adolescents are at more risk of diagnosed mood disorder in adulthood, ${ }^{13}$ with OW/OB children and adolescents seeking psychiatric treatment and being diagnosed with depression ${ }^{5}$ and diagnosed bipolar disorders. ${ }^{5,11}$ OW/ OB children/adolescents have been commonly reported to cope with an increased psychiatric burden ${ }^{11}$ and, when psychologically unhealthy, also more likely to report thoughts and attempts of suicide. ${ }^{25}$

Family situations and influences also need to be considered while considering risk factors for childhood OBy and/or developing psychological disorders. ${ }^{12,23}$ Maternal mental health disorders predisposed $\mathrm{OB}$ children to a higher significant risk of anxiety, ${ }^{12}$ and increased psychological and psychosocial stress in families may be a contributing factor for childhood $\mathrm{OBy}{ }^{23}$

\section{ADHD}

ADHD is one of the most common childhood psychiatric disorders and is estimated to affect between $5 \%$ and $10 \%$ of young schoolchildren worldwide. ${ }^{28}$ In relation to ADHD and childhood OBy, Table 4 summarizes 17 studies that are currently reviewed. Study designs included longitudinal, ${ }^{29-32}$ cross-sectional, ${ }^{33-37}$ cohort, ${ }^{38-41}$ retrospective documentary analysis, ${ }^{5,42,43}$ and secondary analysis. ${ }^{44}$

ADHD diagnosis was confirmed through diagnostic/ clinical interview in 11 studies $^{5,29,31,33,34,37-39,41-43}$ and through ADHD-focused checklists and scales in 6 studies. . $^{30,32,35,36,40,44}$ Self-reporting was recognized to be a limitation in 1 study. ${ }^{40}$ Body weight status was determined using either national ${ }^{5,31,33,35,38,41-44}$ or international reference data and cutoff points criteria. ${ }^{29,30,32,36,37,39}$

Numerous studies have reported associations between ADHD and childhood OBy. ${ }^{14,30-32,35,37}$ The strength of association between $\mathrm{ADHD}$ and childhood OBy varies across research studies. When compared to the general population, only 2 studies reported a significant association between OBy and ADHD symptoms with children/adolescents as assessed by clinical diagnosis $\mathrm{s}^{35,43}$ and CPRS. ${ }^{33}$ Other studies have reported an increased incidence of $\mathrm{OB}$ children with $\mathrm{ADHD},{ }^{36}$ increased risk of becoming $\mathrm{OB},{ }^{29,30,32}$ and increased odds of children with ADHD becoming OW when not using ADHD medication. ${ }^{37}$

Children with ADHD and children displaying childhood conduct problems such as disobedience, defiance, aggression, cruelty to others, and destruction of property were prospectively associated with OW/OB young adults..$^{30,31}$ These behaviors in early childhood were also predictive of disproportionate increase in BMI by early adolescence ${ }^{30}$ or early adulthood. ${ }^{31}$

In contrast, a lower incidence of OW/OBy was noted in children with ADHD treatment ${ }^{34}$ while other studies did not find any association between ADHD and OW/OBy. ${ }^{5,40,42,45}$ Young $\mathrm{OB}$ adolescents are also reported to have lower rates of ADHD (self-reported) compared with healthy and underweight 
(UW) groups, ${ }^{40}$ and children diagnosed with ADHD were more likely to be normal-weight or UW than OB. ${ }^{5}$

\section{Other psychological comorbidities}

In relation to other psychological morbidities, Table 5 summarizes 30 studies currently that are reviewed. Study designs included prospective longitudinal, ${ }^{20,31,32,46-48}$ crosssectional, ${ }^{15,16,21,49-54}$ cohort, ${ }^{24,55-63}$ and retrospective cohort/ documentary analysis. , $^{517,64-66}$

Diagnosis of related psychological comorbidities was confirmed either through diagnostic or clinical interview in 6 studies $^{5,15-17,53,64}$ or through specifically focused questionnaires in 24 studies. ${ }^{20,21,24,31,32,46-52,54-63,65,66}$ All the studies obtained BMI data and determined weight status using national and international reference data and cutoff points criteria.

\section{Self-esteem}

Study findings confirmed that OW/OB children had significantly lower self-esteem than normal-weight peers, as measured by various focused questionnaires..$^{21,49,54}$ Findings confirmed that a clear negative impact on self-esteem was associated with OW/OB children ${ }^{49,54}$ who were more likely to have an increased child body dissatisfaction ${ }^{21,54}$ and lower perceived self-worth and self-competence than normal-weight peers. ${ }^{49}$

Findings are mixed in relation to gender issues. ${ }^{20,49} \mathrm{OB}$ girls completing a self-perception profile, compared with $\mathrm{OB}$ boys, had significantly more negative perceptions of their physical appearance, self-worth, and how they felt they were accepted by social groups, including their peers. ${ }^{49}$ In contrast, no sex differences were found between psychological factors and weight problems with both sexes reporting the association with low self-esteem and OBy. ${ }^{20}$ Self-esteem of OB children also appears to decrease with age with older children reporting significant reduction in self-esteem related to physical appearance than younger children. ${ }^{21,67}$ It is interesting to note that parenting is not associated with child body dissatisfaction but parental responsiveness to OW/OBy is positively associated with child self-esteem..$^{54}$

\section{Health-related quality of life (HRQoL)}

In research studies, childhood OBy is consistently associated with a poorer HRQoL when compared with lower-weight children. ${ }^{24,47,48,51,55,62,63,66}$ The findings for HRQoL tended to be consistent across the studies for both boys and girls. However, sex differences were noted in a study with OB treatment seeking patients with females reporting poorer $\mathrm{HRQoL},{ }^{62}$ and females also reported lower HRQoL compared with males and healthy-weight females. ${ }^{55}$ Severely OB children also reported depressive symptomology in the clinical range as assessed by Becks Depression Inventory Scale and marked impairments in both generic QoL ${ }^{66}$ and HRQoL. ${ }^{24,63,66}$ The association between increasing BMI and lower HRQoL being reported became stronger in later childhood. ${ }^{51}$

\section{Conduct and stigmatization}

OW/OB children were more likely to experience multiple and clinically significant associated psychosocial problems than their healthy-weight peers ${ }^{5,21}$ with increasing conduct issues/ disorders (such as disobedience, disruptive aggressive and destructive behavior, physical and verbal abuse).$^{5,17,31,52}$ Other issues include peer problems, ${ }^{51,52,60}$ inattention issues ${ }^{32}$ along with emotional symptoms. ${ }^{51,60}$ The association between symptoms and OW/OBy was found to be stronger with increasing age in childhood, ${ }^{51}$ with increasing weight at younger ages (4-5 years) and associated with peer relationship problems at age $8-9$ years. ${ }^{61}$

Bullying and teasing, manifestations of OB stigma, were stressors associated with negative psychological outcomes and occurred more frequently in OW children. ${ }^{68}$ Studies reported that persistent intense teasing and bullying experienced from childhood influences psychological complications. ${ }^{15,16,58,59,69} \mathrm{OW} / \mathrm{OB}$ adolescents most distressed by weight-related teasing exhibited lower self-esteem ${ }^{56,59}$ and higher depressive disorders. ${ }^{56,58,59}$ Primary sources of stigma for children and adolescents were reported to include peers, teachers/educators, parents, and health care providers. ${ }^{58,69-71}$ OW/OB children being bullied and teased may also have less favorable conduct and poorer school performance, social circumstances, and social involvement when compared with normal-weight children. ${ }^{70}$ Research findings reported that OW/OB children between 6 and 13 years were $4-8$ times more likely to be teased and bullied than normal-weight peers. ${ }^{21}$ OBy- and weight-related teasing is a significant risk factor for the development of psychosocial problems, including weightbased teasing, social stigmatization/peer rejection, ${ }^{50}$ and later eating disorders and unhealthy weight-control behaviors. ${ }^{58}$

\section{Eating disorders}

There is a clear overlap with OBy and eating disorders in several areas of psychosocial impairment with girls being more vulnerable to comorbid mood and eating problems. ${ }^{72}$ Research findings revealed that $25 \%$ of OB girls used extreme weight-control behaviors such as inducing vomiting, abusing laxatives, diet pills, fasting, or smoking. ${ }^{46}$ The relationship between OBy and eating behaviors in children/adolescents is evident with $\mathrm{OB}$ adolescents clearly at risk of developing a restrictive-eating disorder. ${ }^{64,65}$ There is a very high prevalence rate of mood disorders and significantly higher lifetime 
prevalence of bulimia nervosa in weight-loss-seeking patients with childhood OBy onset. ${ }^{64}$ Studies have reported that OW/ OB children and adolescents were more likely to report higher body dissatisfaction, ${ }^{21,54}$ display extreme dieting behaviour ${ }^{47}$ and eating disorder symptoms, and clinically significant associated psychosocial problems than healthy-weight peers. ${ }^{21}$

\section{Prevention and interventions}

Available evidence confirms that obesity can be treated effectively in younger children ${ }^{73}$ and adolescents. ${ }^{74}$ Multicomponent interventions targeting physical activity and healthy diet could benefit OW/OB children specifically in overall school achievement, ${ }^{73}$ and family-based intervention with maintenance follow-up can improve psychosocial and physical QoL. ${ }^{74}$ Systematic attempts to manage and treat OW in the early years and pre-school years are required ${ }^{47} \mathrm{~A}$ key focus on interventions should be on childhood/adolescent mental health, improving knowledge, and implementing high standard of treatment for OW children. ${ }^{75}$ This needs to involve psychological and social support from families with recommendations about changing lifestyle. ${ }^{23}$ In children with disruptive behavior disorders, secondary prevention and management strategies should include promoting healthy eating and physical activity to prevent adult OBy. ${ }^{19,44}$

\section{Screening recommended}

- Routine screening of children with further comprehensive screening for high-risk populations.

- Specific screening for various interrelated symptoms including OW/OBy, symptoms of impulsive eating behaviors, psychiatric disorders, psychological disturbances, and conduct-related issues.

- Systematic screening for ADHD in OB adolescents with bulimic behaviors. ${ }^{33}$

\section{Early identification and intervention}

- Treating children and female anxiety and depression may be an important effort in the prevention of obesity. ${ }^{14,71}$

- Physicians, parents, and teachers should be informed of specific comorbidities associated with childhood OBy to target interventions that could enhance well-being. ${ }^{50}$

Interventions should recognize individual differences in terms of identifying motivating goals for accomplishing weight management. ${ }^{61}$ Follow-up support is essential to maintain any straying from the short-term effects gained. ${ }^{76}$

- Family interventions need to focus on parenting/attachment issues, behavioral factors, or self-management interventions to implement healthy lifestyles. ${ }^{57}$
- Stigma-reduction efforts are needed to improve attitudes toward OBy.

Motivational interviewing in the treatment of obesity provides a more guiding style encouraging individuals to explore and understand their own intrinsic barriers and incentives to change. ${ }^{61,77}$

\section{Future research}

Future research needs well-designed prospective and hypothesis-driven longitudinal studies to further investigate specific areas (with different populations) and psychiatric and psychological outcomes. Appropriate control groups of clinical or nonclinical populations need to be included. Examples of future research in childhood obesity include further investigation of:

- ADHD: 1) causality in the relationship between ADHD and OBy, and psychopathological pathways linking the two conditions; 2) experimental designs to establish cause and effect for BMI and HRQoL;51 3) cause and effect of causal link between bulimic behaviors and ADHD and potential common neurobiological alterations; ${ }^{33}$ 4) OBy risks of young adults who manifest conduct problems in early life. ${ }^{31}$

- Body image: directional nature of relationships between body image and OBy as well as changes in psychosocial functioning. ${ }^{24}$

- Family functioning: influencing role and extent of parental, family functioning, peer, educator, or societal-related factors in psychological consequences. ${ }^{12}$

- Depression: 1) directional nature of sedentary behavior and onset of depression; ${ }^{19,78}$ 2) moderating versus mediating roles of variables such as trait negative effect, depressive and anxiety symptoms, and low self-esteem and their influence on eating pathology. ${ }^{56}$

- Psychosocial: 1) role of psychosocial factors and treatment interventions that target extremely $\mathrm{OB}$ individuals based on their BMI, and socio-demographic profiles; 2) eating patterns and the dynamic relationship between binge eating and BMI.

- Lifestyle: 1) causal relationships between physical activity behavior, motivation to change, BMI change and development of comorbid health conditions; ${ }^{24} 2$ ) optimal strategies for encouraging lifestyle change and accomplishing weight management. ${ }^{61,77}$

\section{Discussion}

The purpose of this review was to focus on research findings related to psychiatric, psychological, and psychosocial consequences of childhood OBy from an international perspective. 
The precise extent of these complications remains uncertain due to the range of methodological approaches and methods used across studies. Causal mechanisms are not yet fully understood or convincing, but they are likely to involve a complex interplay of biological, psychological, and social factors.

Compared to healthy-weight children and adolescents, there seems to be a consistent heightened risk of psychological comorbidities including depression, compromised perceived QoL, depression and anxiety, self-esteem, and behavioral disorders. In turn, these disorders associated with OBy have a consistent adverse impact on their perceived HRQoL and psychiatric, psychological, and psychosocial disorders. These can be enduring in nature and may continue into adult life with the potential for lifelong health problems.

In general, consistent findings have established that childhood OW/OBy was negatively associated with psychological comorbidities, such as depression, poorer perceived HRQoL, emotional and behavioral disorders, and self-esteem during childhood. Findings are similar to other reviews in this period $^{3,28,45,72,79-82}$ in that $\mathrm{OW} / \mathrm{OB}$ children and adolescents were more likely to experience psychological problems than healthy-weight peers. Findings suggest a shared link between depression and obesity such that OBy increases the risk of depression in adult life, but also that depression predicts the development of obesity. ${ }^{26}$

Evidence related to the psychiatric disorder, ADHD, remains unconvincing because of various findings from studies. Many studies did report an association between ADHD and elevated weight status. ${ }^{14,30-32,35,37}$ Children presenting with early and persistent ADHD in early and mid-childhood are also at an increased risk of OBy in adult life. ${ }^{28}$ Therefore, the child with ADHD may be at risk of becoming OW or the OW child may be at risk for a diagnosis of ADHD. Some studies did not report any association between ADHD and OW/ OBy. ${ }^{5,40,42,45}$ Other reviews also reported that the data were insufficient and inconsistent. . $^{3,4}$

This review found that OW children were more likely to experience multiple associated psychosocial problems than their healthy-weight peers. The strength of association between psychological disorders, psychosocial problems, and OW may also depend upon OBy stigma, teasing, and treatment-seeking children. ${ }^{66,71,82,83}$ This stigmatization is now a common event within society and may be evidenced in the form of negative stereotypes, victimization, and social marginalization. ${ }^{83}$ OBy stigma and teasing/bullying are pervasive and can have serious consequences for emotional and physical health. Stigma may be linked to obesity being the target of many public health campaigns that influence young $\mathrm{OW} / \mathrm{OB}$ children and adolescents to control their weight, often through drastic measures. ${ }^{46,83}$ This means that psychiatric symptoms or disorders may be a consequence of being OB in a culture that stigmatizes OBy. Alternatively psychiatric disorders may contribute to the development of obesity in vulnerable individuals. ${ }^{84}$

Intervention and action are necessary to prevent childhood and adolescent OBy. ${ }^{1}$ Children are particularly vulnerable as both obesity and psychiatric conditions often have their origins during this crucial developmental period. ${ }^{79}$ If obesity remains in adolescence, then it is likely to persist into adult life. ${ }^{14,85}$

\section{Conclusion}

The aim of this review was to establish what has recently changed in relation to common psychological consequences associated with childhood OBy. Despite extensive research being undertaken over the previous decade, it remains unclear as to whether psychiatric disorders and psychological problems are a cause or a consequence of childhood obesity. The prevalence of both childhood OW/OBy and associated psychiatric and psychological disorders is increasing, and there is an acute heightened awareness of this serious public health issue in the society and health-related policy. However, it is also still not proven whether common factors promote both obesity and psychiatric disturbances in susceptible children and adolescents. This finding in itself reflects the challenge of researching and understanding the complex factors associated with childhood OBy and psychological well-being. This review has illustrated that $\mathrm{OW} / \mathrm{OB}$ children are more likely to experience the burden of psychiatric and psychological disorders in childhood, adolescence, and possibly into adulthood. A cohesive and strategic approach to tackle the OBy epidemic is necessary to combat this increasing trend which is compromising the health and well-being of the young generation and seriously impinging on resources and economic costs. As a matter of urgency, further focused research is essential to identify the diverse range of mechanisms driving the current increasing trajectory. Reliable and convincing evidence is needed to inform policy, economic regulation interventions, and strategies to prevent $\mathrm{OBy}$ from affecting future generations.

\section{Disclosure}

LM's time on this research was funded by UK Medical Research Council core funding as part of the MRC/CSO Social and Public Health Sciences Unit "Social Relationships and Health Improvement” program (MC_UU_12017/11) 
and "Complexity in Health Improvement" program (MC UU_12017/14). The authors report no other conflicts of interest in this work.

\section{References}

1. World Health Organisation. Obesity and overweight factsheet no. 311. Geneva; 2016.

2. Ng M, Fleming T, Robinson M, et al. Global, regional, and national prevalence of overweight and obesity in children and adults during 1980-2013: a systematic analysis for the Global Burden of Disease Study 2013. Lancet. 2014;384(9945):766-781.

3. Pulgaron ER. Childhood obesity: a review of increased risk for physical and psychological comorbidities. Clin Ther. 2013;35(1):A18-A32.

4. Sanders RH, Han A, Baker JS, Cobley S. Childhood obesity and its physical and psychological co-morbidities: a systematic review of Australian children and adolescents. Eur J Pediatr. 2015;174:715-746.

5. Marks S, Shaikh U, Hilty DM, Cole S. Weight status of children and adolescents in a telepsychiatry clinic. Telemed J E Health. 2009;15(10):970-974.

6. Wilfley DE, Vannucci A, White EK. Early intervention of eating- and weight-related problems. J Clin Psychol Med Settings. 2010;17(4):285-300.

7. Goodman E, Whitaker RC. A prospective study of the role of depression in the development and persistence of adolescent obesity. Pediatrics. 2002;110:497-504.

8. Schwimmer JB, Burwinkle TM, Varni JW. Health-related quality of life of severely obese children and adolescent. JAMA. 2003;289(14):1813-1819.

9. Williams J, Wake M, Hesketh K, Maher E, Walters E. Healthrelated quality of life of overweight and obese children. JAMA. 2005;293(1):70-76.

10. Pine DS, Goldstein RB, Wolk S, Weissman MM. The associations between childhood depression and adulthood body mass index. Pediatrics. 2003;107:1049-1056.

11. Goldstein BI, Birmaher B, Axelson DA, et al. Preliminary findings regarding overweight and obesity in pediatric bipolar disorder. J Clin Psychiatry. 2008;69(12):1953-1959.

12. Roth B, Munsch S, Meyer A, Isler E, Schneider S. The association between mothers' psychopathology, childrens' competences and psychological well-being in obese children. Eat Weight Disord. 2008;13(3):129-136.

13. Sanderson K, Patton GC, MrKercher C, Dwyre T, Vem AJ. Overweight and obesity in childhood and risk of mental disorders: a 20-year cohort study. Aust N Z J Psych. 2011;45:384-392.

14. Anderson SE, Cohen P, Naumova EN, Must A. Association of depression and anxiety disorders with weight change in a prospective communitybased study of children followed up into adulthood. Arch Pediatr Adolesc Med. 2006;160(3):285-291.

15. Bell LM, Byrne S, Thompson A, et al. Increasing BMI z-scores is continuously associated with complications of overweight children, even in healthy weight ranges. J Clin Endocrinol Metab. 2007;92:517-522.

16. Bell LM, Curran JA, Byrne S, et al. High incidence of obesity comorbidities in young children: a cross sectional study. J Pediatr Child health. 2011;47:911-917.

17. Eschenbeck H, Kohlmann CW, Dudey S, Schurholz T. Physician-diagnosed obesity in German 6- to 14-year-olds. Prevalence and comorbidity of internalizing disorders, externalizing disorders, and sleep disorders. Obesity Facts. 2009;2(2):67-73.

18. Anderson SE, Cohen P, Naumova EN, Jacques PF, Must A. Adolescent obesity and risk for subsequent major depressive disorder and anxiety disorder: prospective evidence. Psychosom Med. 2007;69(8):740-747.

19. Anton SD, Newton RL Jr, Sothern M, Martin CK, Stewart TM, Williamson DA. Association of depression with body mass index, sedentary behavior, and maladaptive eating attitudes and behaviors in 11 to 13-year old children. Eat Weight Disord. 2006;11(3):e102-e108.
20. Bjornelv S, Nordahl HM, Homen TL. Psychological factors and weight problems in adolescents. The role of eating problems, emotional problems and personality traits: the Young-HUNT study. Soc Psychiatry Psychiatri Epidemiol. 2011;46(5):353-362.

21. Gibson LY, Byrn SM, Blair E, Davies EA, Jakobi P, Zubrick SR. Clusters of psychological symptoms in overweight children. Aust N ZJ Psych. 2008;42:118-125

22. Hoare E, Millar L, Fuller-Tyszkiewicz M, et al. Associations between obesogenic risk and depressive symptomatology in Australian adolescents: a cross sectional study. J Epidemiol Community Health. 2014;68:767-772.

23. Koch F, Sepa A, Ludvigsson J. Psychological stress and obesity. $J$ Pediatr. 2008;153:839-844.

24. Phillips BA, Gaudette S, McCracken A, et al. Psychosocial functioning in children and adolescents with extreme obesity. J Clin Psychol Med Settings. 2012;19(3):277-284.

25. van Wijnen LG, Bolujit PR, Hoeven-Mulder HB, Bernelmans WJ, Wndel-Vos GC. Weight status, psychological health, suicidal thoughts, and suicide attempts in Dutch adolescents: results from the 2003 E-MOVO project. Obesity. 2010;18:1059-1061.

26. Luppino FS, de Wit LM, Bouvy PF, et al. Overweight, obesity, and depression: a systematic review and meta-analysis of longitudinal studies. Arch Gen Psychaitr. 2010;67:220-229.

27. Swanson SA, Crow S, Le Grange D, et al. Prevalence and correlates of eating disorders in adolescents. Arch Gen Psychiatry. 2011;68(7):714-723.

28. Cortese S, Angriman M, Maffeis C, et al. Attention-deficit/hyperactivity disorder (ADHD) and obesity: a systematic review of the literature. Crit Rev Food Sci Nutr. 2008;48(6):524-537.

29. Anderson SE, Cohen P, Naumova EN, Must A. Relationship of childhood behavior disorders to weight gain from childhood into adulthood. Ambul Pediatr. 2006;6:297-301.

30. Anderson SE, He X, Schoppe-Sullivan S, Must A. Externalizing behavior in early childhood and body mass index from age 2 to 12 years: longitudinal analyses of a prospective cohort study. BMC Pediatr. 2010;10:49.

31. Duarte CS, Sourander A, Nikolakaros G, et al. Child mental health problems and obesity in early adulthood. J Pediatr. 2010;156(1):93-97.

32. Khalife N, Kantomaa M, Glover V, et al. Childhood attention-deficit/ hyperactivity disorder symptoms are risk factors for obesity and physical inactivity in adolescence. JAm Acad Child Adolesc Psychiatry. 2014;53(4):425-436.

33. Cortese S, Isnard P, Frelut ML, et al. Association between symptoms of attention-deficit/hyperactivity disorder and bulimic behaviors in a clinical sample of severely obese adolescents. Int $J$ Obes. 2007;31(2):340-346.

34. Dubnov-Raz G, Perry A, Berger I. Body mass index of children with attention-deficit/hyperactivity disorder. J Child Neurol. 2011;26(3):302-308.

35. Erhart M, Herpertz-Dahlmann B, Wille N, Sawitzky-Rose B, Hölling $\mathrm{H}$, Ravens-Sieberer U. Examining the relationship between attentiondeficit/hyperactivity disorder and overweight in children and adolescents. Eur Child Adolesc Psychiatry. 2012;21(1):39-49.

36. Kim J, Mutyala B, Agiovlasitis S, Fernhall B. Health behaviors and obesity among US children with attention deficit hyperactivity disorder by gender and medication use. Prev Med. 2011;52(3-4):218-222.

37. Waring ME, Lapane KL. Overweight in children and adolescents in relation to attention-deficit/hyperactivity disorder: results from a national sample. Pediatrics. 2008;122(1):e1-e6.

38. Byrd HCM, Curtin C, Anderson SE. Attention-deficit/hyperactivity disorder and obesity in US males and females, age 8-15yrs: National Health and Nutrition Examination Survey 2001-2004. Pediatr Obes. 2013;8:445-453.

39. Graziano PA, Bagner DM, Waxmonsky JG, Reid A, McNamara JP, Geffken GR. Co-occurring weight problems among children with attention deficit/hyperactivity disorder: the role of executive functioning. Int $J$ Obes. 2012;36(4):567-572. 
40. Rojo L, Ruiz E, Dominquez JA, Calaf M, Livianos L. Comorbdiity between obesity and attention deficit/hyperactivity disorder: population study with 13-15 year olds. Int J Eat Disord. 2006;3:519-522.

41. Yang R, Mao S, Zhang S, Li R, Zhao Z. Prevalence of obesity and overweight among Chinese children with attention deficit hyperactivity disorder: a survey in Zhejiang province, China. BMC Psychiatry. 2013;13(133):13-133.

42. Pauli-Pott U, Neidhard J, Heinzel-Gutenbrunner M, Becker K. On the link between attention deficit/hyperactivity disorder and obesity: do comorbid oppositional defiant and conduct disorder matter? Eur Child Adolesc Psychiatry. 2014;23(7):531-537.

43. Racicka E, Hanc T, Giertuga K, Brynska A, Wolanczyk T. Prevalence of overweight and obesity in children and adolescents with ADHD: the significance of comorbidities and pharmacotherapy. J Atten Disord. Epub 20 April, 2015.

44. White B, Nicholls D, Christie D, Cole TJ, Viner RM. Childhood psychological function and obesity risk across the lifecourse: findings from the 1970 British Cohort Study. Int J Obes. 2012;36(4):511-516.

45. Nigg JT, Johnstone JM, Musser ED, Galloway Long H, Willoughby MT, Shannon J. Attention-deficit/hyperactivity disorder (ADHD) and being overweight/obesity: new data and meta-analysis. Clin Psychol Rev. 2016;43:67-79.

46. Neumark-Sztainer D, Wall M, Haines J, Story M, Sherwood NE, van der Berg P. Shared risk and protective factors for overweight and disordered eating in adolescents. Am J Prev Med. 2007;33:359-369.

47. Wake M, Canterford L, Patton GC, et al. Comorbidities of overweight/ obesity experienced in adolescence: longitudinal study. Arch Dis Child. 2010;95(3):162-168

48. Wake M, Clifford SA, Patton GC, et al. Morbidity patterns among the underweight, overweight and obese between 2-18yrs: population-based cross-sectional analysis. Int J Obes. 2013;37:86-93.

49. Franklin J, Denyer G, Steinbeck KS, Caterson ID, Hill AJ. Obesity and risk of low self-esteem: a statewide survey of Australian children. Pediatrics. 2006;118:2481-2487.

50. Halfon N, Larson K, Slusser W. Associations between obesity and comorbid mental health, developmental, and physical health conditions in a nationally representative sample of US children aged 10 to 17. Acad Pediatr. 2013;13(1):6-13.

51. Jansen PW, Mensah FK, Clifford S. Bidirectional associations between overweight and health-related quality of life from 4-11 years: Longitudinal Study of Australian Children. Int J Obes (Lond). 2013; 37(10):1307-1313.

52. Sawyer MG, Miller-Lewis L, Guy S, Wake M, Canterford L, Karlin JB. Is there a relationship between overweight and obesity and mental health problems in 4-5yr old Australian children. Ambul Pediatr. 2006;6:306-311.

53. Taner Y, Torel-Ergur A, Bahcivan G, Gurdag M. Psychopathology and its effect on treatment compliance in pediatric obesity patients. Turkish J Pediatr. 2009;51(5):466-471.

54. Taylor A, Wilson C, Slater A, Mohr P. Self-esteem and body dissatisfaction in young children and associations with weight and parenting style. Clin Psychol. 2012;16:25-35.

55. Bolton K, Kremer P, Rossthorn N, et al. The effect of gender and age on the association between weight status and health-related quality of life in Australian adolescents. BMC Public Health. 2014;14:898.

56. Gerke CK, Mazzeo SE, Stern M, Palmberg AA, Evans RK, Wickham EP 3rd. The stress process and eating pathology among racially diverse adolescents seeking treatment for obesity. J Pediatr Psychol. 2013;38(7):785-793.

57. Johnston CA, Fullerton G, Moreno JP, Tyler C, Foreyt JP. Evaluation of treatment effects in obese children with co-morbid medical or psychiatric conditions. Georgian Med News. 2011;(196-197):93-100.

58. Madowitz J, Knatz S, Maginot T, Crow SJ, Boutelle KN. Teasing, depression and unhealthy weight control behaviour in obese children. Pediatr Obes. 2012;7(6):446-452.

59. Quinlan NP, Hoy MB, Costanzo PR. The effects of teasing on psychosocial functioning in an overweight treatment-seeking sample. Soc Dev. 2009;18:978-1001.
60. Sawyer MG, Harchark T, Wake M, Lynch J. Four year prospective study of BMI and mental health problems in children. Pediatrics. 2011; 128:677-684.

61. Walders-Abramson N, Nadeau KJ, Kelsey MM, et al. Psychological functioning in adolescents with obesity co-morbidities. Child Obes. 2013; 9(4):319-325

62. Wille N, Bullinger M, Holl R, et al. Health-related quality of life in overweight and obese youths: results of a multicentre study. Health Qual Life Outcomes. 2010;8:36-44.

63. Zeller MH, Modi AC. Predictors of health-related quality of life in obese youths. Obesity (Silver Spring). 2006;14:122-130.

64. Guerdjikova AI, McElroy SL, Kotwal R, Stanford K, Keck PE Jr. Psychiatric and metabolic characteristics of childhood versus adult-onset obesity in patients seeking weight management. Eat Behav. 2007;8(2):266-276.

65. Lebow J, Sim LA, Kransdorf LN. Prevalence of a history of overweight and obesity in adolescents with restrictive eating disorders. $J$ Adolesc Health. 2015;56(1):19-24.

66. Zeller MH, Roehrig HR, Modi AC, et al. Health-related quality of life and depressive symptoms in adolescents with extreme obesity presenting for bariatric surgery. Pediatrics. 2006;117:1155-1161.

67. Daniels SR, Jacobson MS, McCrindle BW, et al. American Heart Association childhood obesity research summit report. Circulation. 2009;119:e489-e517.

68. Neumark-Sztainer D, Falkner N, Story M, Perry C, Hannan PJ, Mulert S. Weight-teasing among adolescents: correlations with weight status and disordered eating behaviors. Int J Obes Relat Metab Disord. 2002; 26:123-131.

69. Hayden-Wade HA, Stein RI, Ghaderi A, Saelens BE, Zabinski MF, Wilfley DE. Prevalence, characteristics, and correlates of teasing experiences among overweight children vs. non-overweight peers. Obes Res. 2005;13(8):1381-1392.

70. Maloney AE. Pediatric obesity: a review for the child psychiatrist. Child Adolesc Psychiatr Clin N Am. 2010;19:353-370.

71. Puhl RM, Latner JD. Stigma, obesity, and the health of the nation's children. Psychol Bull. 2007;133(4):557-580.

72. Rancourt D, McCullough MB. Overlap in eating disorders and obesity in adolescence. Curr Diabet Rep. 2015;15(10):78.

73. Martin A, Saunders DH, Shenkin SD, Sproule J. Lifestyle intervention for improving school achievement in overweight or obese children and adolescents. Cochrane Database Syst Rev. 2014;(3):CD009728.

74. Fenner AA, Howie EK, Davis MC, Straker LM. Relationships between psychosocial outcomes in adolescents who are obese and their parents during a multi-disciplinary family-based healthy lifestyle intervention: one year follow-up of a waitlist controlled trial. Health Qual Life Outcomes. 2016;14:100-116.

75. Barlow SE. Expert Committee. Expert committee recommendations regarding the prevention, assessment and treatment of child and adolescent overweight and obesity: summary report. Pediatrics. 2007;120(Suppl):S164-S192.

76. Wilfley DE, Stein RI, Saelens BE, et al. Efficacy of maintenance treatment approaches for childhood overweight: a randomized controlled trial. JAMA. 2007;298(14):1661-1673.

77. Armstrong MJ, Mottershead TA, Ronksley PE, et al. Motivational interviewing to improve weight loss in overweight and/or obese patients. A systematic review and meta-analysis of randomized controlled trials. Obes Rev. 2011;12:709-723.

78. Reilly JJ, Armstrong J, Dorosty AR, et al. Early life risk factors for obesity in childhood: cohort study. BMJ. 2005;330:1357.

79. Kalarchian MA, Marcus MD. Psychiatric comorbidity of childhood obesity. Int Rev Psychiatry. 2012;24(3):241-246.

80. Harriger JA, Thompson JK. Psychological consequences of obesity: weight bias and body image in overweight and obese youth. Int Rev Psychiatry. 2012;24(3):247-253.

81. Kalra G, De Sousa A, Sonovane S, Shah N. Psychological issues in pediatric obesity. Ind Psychiatry J. 2012;21:11-17.

82. Wardle J, Williamson S, Johnson F, et al. Depression in adolescent obesity: cultural moderators of the association between obesity and depressive symptoms. Int J Obes. 2006;30:634-643. 
83. Tang-Péronard JL, Heitmann BL. Stigmatization of obese children and adolescents, the importance of gender. Obes Rev. 2008;8(6): 522-534.

84. Gadalla T, Piran N. Psychiatric comorbidity in women with disordered eating behavior: a national study. Women Health. 2008;48(4): $467-484$.

85. Reilly JJ. Long term impact of overweight and obesity in childhood and adolescence on morbidity and premature mortality in adulthood; systematic review. Int J Obes. 2011;35(7):891-898.

86. National Center for Health Statistics. Health, United States, 2011: With Special Features on Socioeconomic Status and Health. Hyattsville, MD; 2012.
87. Ogden CL, Carroll MD, Kit BK, Flegal KM. Prevalence of childhood and adult obesity in the United States, 2011-2012. JAMA. 2014;311(8): 806-814.

88. World Health Organisation. A Snapshot of the Health of Young People in Europe. Geneva: European Commission Conference on Youth Health; 2009.

89. Sassi F, Devaux M, Cecchini M, Rusticelli E. The obesity epidemic: analysis of past and projected future trends in selected OECD countries. Paris Cedex: OECD Publishing; 2009.

90. Australian Bureau of Statistics. Australian Health Survey: updated results, 2011-2012; 2013. Available from: http://www.abs.gov.au/ausstats/ abs@.nsf/Lookup/4364.0.55.003main+features12011-2012. Accessed July 1, 2016.

\section{Publish your work in this journal}

Adolescent Health, Medicine and Therapeutics is an international, peer-reviewed, open access journal focusing on health, pathology, and treatment issues specific to the adolescent age group. All aspects of health maintenance, preventative measures and disease treatment interventions are addressed within the journal and practitioners from all disciplines are

Submit your manuscript here: http://www.dovepress.com/adolescent-health-medicine-and-therapeutics-journal

invited to submit their work as well as healthcare researchers and patient support groups. This journal is included in PubMed. The manuscript management system is completely online and includes a very quick and fair peer-review system. Visit http://www.dovepress.com/testimonials. php to read real quotes from published authors. 